\title{
Preparing to Work: Dramaturgy, Cynicism and Normative Control in the Socialization of Graduate Recruits in Management Consulting
}

David Poulter and Chris Land

Author for correspondence:

Dr. Chris Land

Department of Accounting, Finance and Management

University of Essex

Wivenhoe Park

Colchester

CO4 3SQ

email-cland@essex.ac.uk 


\begin{abstract}
This paper examines the socialization of graduate recruits into a knowledge intensive labour process and organizational culture. Theoretically the paper draws upon the idea of "preparing for work' to position this early socialization as a crucial moment in the production of subjectivities suited (and booted) for the labour process of management consulting. Empirically the paper reports on a two day induction session for new graduate recruits joining a global management consultancy and their responses to this training. Particular attention is given to the use of roleplay and a dramaturgical workshop used in part of the training process. The paper argues that the utilization of dramaturgy in training is consistent with the overall approach to control developed in the firm in response to the fact that the labour process of consulting is often conducted on client sites, away from any direct supervisory gaze. As such the consultants were subjected to a form of cultural control that was designed to function independent of direct supervision. This control did not operate directly upon the new employees professed values, however, but at one step removed so that a 'cynical distance' from the content of the organization's culture was accepted so long as a professional 'ethic of behaviour' was established. By focusing on an 'ethic of behaviour' these young professionals were encouraged to internalize a self-control akin to that of an actor, rather than internalizing the corporate values directly.
\end{abstract}

Key words: management consulting, cultural control, cynicism, training, socialization, subjectivity 


\section{Introduction}

Since the 1980s there has been a wealth of organizational research examining forms of control that focus on the production of workers' subjectivities. Initiatives such as corporate culture (Ray, 1986; Kunda, 1992; Willmott, 1993; Casey, 1995; Gabriel, 1999), teamworking (Barker, 1993; 1999) and quality management (Sewell and Wilkinson, 1992; Knights and McCabe, 2000) have all sought to extend control from an external relation of coercion to an internalized form of self-control. In implementing these forms of control a wide range of discursive technologies and organizational arrangements have been utilised by management to align employees' desires and subjectivities with the interests of 'the organization' (in most cases this equates to the financial interests of external shareholders). Whilst the efficacy of these measures - whether they elicit a genuine change in employees subjectivity or merely behavioural compliance, and the extent and effectiveness of employee resistance - has been a matter of some debate, it is clear is that employees' subjectivity is a significant and contested terrain in contemporary organizations (Collinson, 2003; Ogbonna and Harris, 1998; Fleming and Spicer, 2003; McCabe, 2000; Jermier, 1998; Ackroyd and Thompson, 1999).

This paper contributes to this literature on control and subjectivity at work by adding to the still relatively small number of empirical studies of control over white-collar, professional work (e.g. Ross, 2003; Robertson and Swan, 2003; Grey, 1994; Watson, 1994; Kunda, 1992) and by contributing to studies of cynicism and distancing in the production of workplace subjectivities (Fleming and Spicer, 2003; Fleming, 2005). The empirical study is of a two-day induction programme for new recruits joining a globally renowned management consultancy firm, here given the pseudonym ICU. In examining the preparation of new graduate recruits for the work of consultancy we attend to both the form and content of the training session. Through the interrelation of form and content a process of subjectivization emerges that ensures new recruits actively align their behaviours and professional identity with the interests of the organization despite, or even because of, a splitting of subjectivity through a combination of cynical and dramaturgical distancing. In contrast to recent studies of resistance which emphasise the potential for cynicism to actively craft an 'emancipatory space within relations of domination' (Fleming, 2005: 55) we suggest that, through dramaturgy and cynicism, the consultants' crafting 
of subjectivity was managed to elicit both an extremely effective form of behavioural control and a deeper form of subjectivization functioning through the new consultants' nascent sense of professional identity, but at one step removed from the espoused values of the official corporate culture.

\section{Shifting forms of production: the value of control}

Much of the literature on subjectivity and control to date has followed Marx in his pivotal descent into the workplace in chapter six of Capital volume 1 (1979: 279-80; Braverman, 1974; Burawoy, 1982; Jaros and Sells, 2004). For Marx the key to understanding the production of value in a capitalist economy was to analyse the social relations at the point of production. It was here that the unique commodity of labour-power was put to work and its use-value - the ability to produce surplus-value - was realised. This focus on the production of commodities, whether tangible products or less tangible services, has remained a key focus for studies of contemporary control at work, as evinced by Barker's $(1993 ; 1999)$ studies of teamworking, Sewell and Wilkinson's (1992) study of Just-in-Time and quality management, and Casey's (1995) study of cultural control. A similar focus is found in the numerous studies of call centres that have appeared over the last decade in which attention has primarily been paid to the techniques of control employed directly at the point of production where the operative is dealing with calls (Taylor and Bain, 1999; Frenkel et al, 1998). Whilst the point of production clearly remains a significant focus both for the production of value and for research, not least because this is still the main activity for most employees throughout the working day, Marx's original rationale for this focus has recently been questioned and researchers have turned their attention to issues of recruitment and training (Callaghan and Thompson, 2002). As this paper argues, one of the main foci for training, at least in management consulting, is the formation of subjectivity and its alignment with corporate value systems.

Even where the point of production is still the main focus, control through culture and identity can be found in numerous examples from across the service sector (Hancock and Tyler, 2001; Leidner, 1999; Hardt and Negri, 2000: 290; Thompson et al, 2001) and is particularly prominent in knowledge intensive firms and industries (Robertson and Swan, 2003; Ross, 2003; Grey, 1994). One such industry is management consulting where the labour process is itself often 
distributed and conducted away from the home office on a client's premises (Böhm, 2003: 21). If capital is to maintain control over such distributed labour processes, then control must extend beyond the point of production into the formation of workers' subjectivity so as to secure effective remote control. This production of producers is arguably one of the paradigmatic forms of the exercise of control over contemporary labour processes (Dyer-Witheford, 1999: 100-112).

Of course, the point of commodity production is one crucial site where producers are reproduced daily but it is not the only site and by the time most workers arrive at the point of production they have been well prepared for work. This point is well recognized in more sociologically informed studies of labour, such as Paul Willis' study of socialization into unskilled labour which emphasised the interconnected network of institutions, including school and family, that reproduced 'class' and working-class subjectivity through lines of filial descent (Willis, 1978). Studies of cultural control within the workplace have also broadened their analysis to incorporate networks of subjectivization that extend well beyond the factory walls and into the local community, education, class and gender identities (Glucksmann, 2000; Collinson, 1992; Ackroyd and Crowdy, 1990). Several studies of professional labour processes have similarly extended their purview, analysing how workers' subjectivities are prepared for work before they even enter the workplace, for example, through forms of anticipatory socialization and through careers advice at school and CV writing (Metcalfe, 1994), through more socially diffuse discourses such as 'career' and entrepreneurial projects of the self (Grey, 1994: 482) and through institutions of higher education (Harvie, 2006; Harney, 2007). This study contributes to this broad literature on 'preparing to work' by focusing on the bridging activity of training and induction where new recruits are first oriented toward the behaviours and performances expected of them in their new role, often their first 'serious' role, as employees.

\section{Preparing for Work: Subjectivity and Performance}

It is through training that new and extant employees are initially 'prepared for work' or produced as capable and willing workers. Of course, in many industries training is a relatively small element of control. In McDonalds', for example, control is predominantly exercised through direct supervision and machine-controlled work so that 'training' is little more than a 10 minute 
video on operating an automatic chip-frier (Garson, 1988). With more knowledge intensive labour processes however training is a key element in the production process, second only to selection (Callaghan and Thompson, 2002). For knowledge-intensive firms (Alvesson, 2004) the collective expertise of the workforce constitutes their primary asset and therefore their competitive positioning 'is entirely dependent on creating and sustaining a loyal expert workforce' (Robertson and Swan, 2003:835). Training is thus often simultaneously technical and normative, particularly early training as new recruits are socialised into the behavioural norms and forms of conduct that characterise the company and the successful performance of an 'expert' or 'professional' identity (Lave and Wenger, 1991). As Chris Grey (1994) has noted, when combined with the idea of a career such normative controls are not simply foist upon employees but are actively participated in as a project of the self. Nevertheless, and as our case study demonstrates, this self-production is riddled with contradictions and tensions as employees seek to maintain a coherent sense of self and engage in active impression management. By adopting the mien of an actor and consciously performing in accordance with expected forms of behaviour, employees are able to project the appearance of a competent, enthusiastic and professional employee necessary for a successful career, whilst also sustaining a sense of self outside this game of appearances. This split subjectivity can offer some defense against the precariousness of contemporary employment, even for relatively high-status professionals and knowledge workers (Cohen and Taylor, 1992; Collinson, 1992; cf. Fleming, 2005).

In the rest of the paper we explore some of these tensions through a case study of training and induction for recent graduates joining a large management consulting firm: ICU. Over two intense days these recruits were introduced to the ethos and working practices of ICU and were subjected to the first of many episodes of hierarchical and peer surveillance as their behaviour and performance were assessed and measured against corporate standards. In the process of projecting the required identity of a 'professional' and performing as enthusiastic, competent and self-possessed employees, the recruits were active in their constructions of self, seeking to present the image they believed trainers wanted to see and which would ensure them of career success. The trainers in turn sought to use the training situation to inculcate within the recruits a sense of the performances expected and to facilitate the preliminary surveillance and assessment of these behaviours. As interviews with the new recruits demonstrated, however, their 
performances coexisted, somewhat uneasily, with a desire to protect, or perhaps produce (Fleming, 2005), a separate, sometimes quite cynical, sense of self independent from, and acutely aware of, corporate control. This sphere of apparent autonomy is particularly important given the relatively small numbers of graduates who succeed and remain with the company. In distancing themselves from the normative control developed in the training session, the new recruits were able to partially protect their sense of self against potential future rejection by the firm. We also suggest that this distance enabled the content of the corporate culture to be changed more readily in the future as consultants were not encouraged to over-identify with the espoused values, enabling a more flexible approach to values and ethics in a changing marketplace.

Despite this apparent distancing from the company's espoused culture and values, the form of the training situation, and particularly the use of dramaturgy to facilitate a reflexive distance from the trainee's own behaviours, combined with a deeper level of content in the value system: a 'professional ethic of behaviour' based upon discipline and self-control. By locating the trainees' performances within this discourse of a 'professional ethic of behaviour', recruits were able to manage the tensions arising from a cynical response to the espoused corporate values, combined with an intensely competitive work environment where continuous surveillance and performance appraisal were endemic. This survival came at a cost, however, as it facilitated a deeper colonisation of subjectivity precisely through the incorporation of a cynical distance (cf. Fleming, 2005). In this the trainees' responses reflect the cynicism that Peter Sloterdijk (1987) has referred to as 'enlightened false consciousness'. They were perfectly able to see through the control mechanisms to which they were subject but would not, or could not, act other than in accord with them. Given the failure of this 'enlightened' awareness of power, and its collapse into cynicism, the paper ends by asking whether critical studies of management and organization, rather than facilitating social change and emancipation through critique, might actually be instilling the seeds of a cynical subjectivity which is perfectly in accord with the ideal recruits sought by companies like ICU (cf. Boltanski and Chiapello, 2005; Fleming, 2006).

\section{Case study and methods}

ICU is a global management consultancy, technology services and outsourcing company. As with most consulting firms, whilst the 'product' they supply to a client may well take the form of 
a customised IT package or other organizational 'solution' the real product on sale is the expertise of its consultants. Unlike some consultancy firms however ICU is of such a size that its brand outweighs the individual expertise of any of its employees. What a client is purchasing is the collective ICU expertise and an individual consultant or business analyst is just one node in the network that produces and applies this distributed intelligence.

To maintain this network, ICU has an annual UK intake of approximately 400 graduates to add to its existing workforce of over 90,000 people based in 48 different countries around the world. New graduate recruits entering the UK consultancy practice of ICU participate in a two-day 'orientation' event held in an outsourced, purpose-built training facility, XVenues, close to ICU's main offices in central London. The orientation event is of a standardized format prescribed by the company's headquarters in the United States and which all new graduate recruits undertake on their first two days of employment with the company. ICU holds several such events throughout the year and around the globe, catering for the large numbers of recruits joining at the 'analyst' level every year. Each event is designed to accommodate around sixty new joiners. Following this preliminary induction new joiners embark on a further three to five weeks of training within their individual operating groups before being assigned to a project team working for an external client. Both work and training is usually conducted away from ICU premises. Work usually takes place at the client site and ICU's training facilities have been outsourced to a dedicated training facility so in their first days with ICU new joiners never set foot inside the organization's own buildings. As most of their subsequent training is hosted in the same facility, and from there they are usually moved directly to a client site, it could well be months before the recruits actually see the insides of an ICU building. This mirrors the reality of work with the company where around $90 \%$ of a consultant's time will be spent at client sites.

The 'orientation' event itself consists of a series of presentations, with varying degrees of interactivity, delivered to joiners by ICU employees from a range of seniority levels, functions and nationalities. Both ICU and XVenues gave us full access to observe the event in its entirety. Observations were recorded in a notebook at the time and were supplemented by informal 
conversations with those involved throughout the two days ${ }^{1}$. In addition to, and informed by, this observation we conducted thirteen formal, semi-structured interviews, eight with new joiners and five with trainers. These interviews were used to explore participants' experiences of and responses to the training situation. Five further interviews were conducted, two with facilitators from ICU-HR, a separate legal entity charged with administering ICU's UK training courses and responsible for organising the induction event, and three with senior managers from the venue provider. The samples were selected to be as representative as possible of the wider population involved with the training in terms of role, ethnicity, gender and age.

\title{
Normative control and the commodification of labour
}

\begin{abstract}
'Analyst - Become an ICU professional, working and behaving in line with our core values and ethics' ('Leadership and Core Values' presentation slide)
\end{abstract}

'Stewardship - Commit, through words and deeds, to our shared vision' ('Leadership and Core Values' presentation slide)

The goals of corporate culture management are well known (Willmott, 1993; Casey, 1995; Robertson and Swan, 2003) and for ICU the main imperative for the induction training was to facilitate recruits' buy-in to ICU values. Of course, this is not unusual and when questioned about the prevalence of such normative content in training events held at XVentures, the founder of the company commented that:

'I'm sure if you discussed that with them, all would say that was a key objective that by the end of $\mathrm{x}$ period people would identify with the firm they had joined'

\footnotetext{
${ }^{1}$ Although our presence as observers, particularly through the interviews and informal discussions, may have had some effect on the trainee's perceptions of the event, if only by opening a small space for reflexive distance, the intensity of the event and the continuous observation and assessment by facilitators, managers and senior consultants from ICU almost certainly dwarfed any influence that we had on the training event. The majority of the formal interviews were conducted after the event, so the reflexive space opened by this dialogue should not have unduly influenced the unfolding of the events in the actual training. During the formal training we kept our presence as observers as low key as possible. As the primary field researcher was of a similar age to many of the recruits, our presence qua observers was also
} 
For ICU the imperative was to ensure a globally consistent product despite the diverse range of cultural backgrounds that new recruits bring to the job. As one of the trainers put it, 'a lot of the material we deliver is driven globally...to help ensure consistency with the messages being presented to people joining the company' (Anna - trainer). However, the description offered by another trainer paints a particularly striking picture of the importance and influence of culture at ICU:

'What [ICU] have got is about 90,000 people across the globe in 47 countries but they all pretty much act in the same way - it's a bit like The Stepford Wives ${ }^{2}$ in a way' (Lara - trainer)

In order to ensure that the product delivered by ICU was consistent, trainers felt it imperative that all employees should share a common set of values. Without these core values, brand consistency across the globe could not be assured and project teams combining consultants from different countries would not have a common base for collaboration. Such a totalising portrait of 'the ICU way' clearly carries strong implications for new joiners who must at least appear to fit in. This pressure was readily recognised by the new recruits.

The first morning's activities comprised three presentations: 'ICU Overview', 'Leadership and Core Values' and 'Brand and Personality'. Participating in these seminars left the joiners in no doubt as to the values they were supposed to adhere to in the performance of their role as a member and representative of the company. Repetition of key themes throughout the two days made sure that the message to the recruits was clear but it also left many of the new analysts with a sense of being 'moulded' and shaped:

'everything [at ICU] is focussed toward trying to mould the person, they're famous for it....That's quite evident this morning because [the content]'s not anything to do with what we're gonna be doing...I think

reduced.

${ }^{2}$ The Stepford Wives, originally a novel by Ira Levin, has been made into a film twice. Both films are set in a US suburb where all the men have identical, beautiful, obedient wives. As the plot unfolds it is revealed that the wives' obedient uniformity is the result of their being controlled by their husbands. In the first version the original wives have been killed and replaced by robots. In the second version the wives are controlled through neural implants. The allusion in this quote is to the uniformity of ICU consultants, who in other contexts we have heard referring 
ICU people are probably mostly recruited around my age, straight to a year out of university, [because they're] easy to mould to a culture' (Adam - trainee)

In addition to these training sessions, ICU have an extremely high profile on university campuses and business schools across the UK, particularly in Russell Group universities. Through sponsorship of everything from student cinema to student industrial societies, where partners in the firm are regular invited speakers, ICU carefully manages a process of anticipatory socialisation ensuring that potential recruits are already well aware of the kind of values and behaviours the firm expects from its employees. The prestige of working for the firm, coupled with this awareness, is sufficient to ensure that recruits willingly subject themselves to the 'moulding' process of cultural control. In so doing, the recruits' responses to cultural control were not a naïve, unquestioning internalization of the ICU values, but an informed, even cynical, recognition of the need to perform according to those values.

The potential benefits of conformity, at least in career terms, are significant. Supporting Adam's view that recent graduates were preferred because they were easier to fit into the firm, one trainer, Claude, told the new starters in the opening presentation, 'You're lucky to come in at junior level because that's our culture, to promote from within.' On their first day with the company, the prospect of future promotion and career success is held out to the new recruits to encourage acceptance of the ICU values: do the job right, fit in and you could make partner. The conjunction of culture and promotion in Claude's comment was no mere coincidence.

\section{Remote Control and the Location of the Consulting Labour Process}

The degree of emphasis placed on joiners' integration into the ICU culture owes much to the nature of the work they will have to perform. The relatively short period before going out to the client site where, in full sight of the client, they would subsequently spend the majority of their time, was perceived by many joiners as a key driver of ICU's upfront focus on culture and values. As one new joiner explained it:

to themselves as 'ICU androids'. 
'because you get into the projects so early - it's not the case that you've got two years in an office somewhere - [they] are essentially taking graduates...into the workplace, [they've] gotta bring them all up to... a uniform level really' (Mark - trainee)

His comments resonate with Adam's (above) concerning ICU's attempt 'to create uniformity which is their key to create success.' In explaining and accepting the need for uniformity both recruits and trainers framed their understanding in relation to the context within which the consulting labour process is conducted. The visibility of analysts at the client site creates an acute need for ICU to integrate joiners into its culture and ensure that they can perform according to the company's values whilst in the field.

Generally the joiners recognised and accepted this requirement as a part of their new job. Jinit, for example, offered the following account of both the approach and its rationale:

'with consulting there is kind of a drive to make you more of say an ICU person or a consulting firm person than with other companies because you are there on the client site and you are the driving force of the company - you are ICU almost' (Jinit - trainee)

The performance of the consulting labour process at the client site also informed the company's decision to conduct early training at an outsourced training venue rather than in the main ICU offices. Being in a non-ICU building parallels the working practices of analysts stationed at the client site. The idea was to acclimatise joiners to 'going to work', both in the sense of physically getting themselves there and emphasising the imperative to 'add value'. As one of the facilitators put it, with a non-residential, external venue 'they start to get a feel for commuting...so it's more like work than a comfy, cosy jaunt away'.

As the recruits would be working at a clients' site, the system of control over their labour would also have to function remotely. Both the choice of training venue and the content of the programme reflected this form of remote control, emphasising the trainees' role as representatives of the company. Recruits experienced this as simultaneously empowering and as an intense pressure to perform. As one of them put it: 
'If I went to an ICU building it's like oh, now I'm a part of ICU. You don't have that here. You have like, you are a fantastic person that can be, you know, so radical that you are ICU even when you're not in an ICU building. Because most of the time afterwards I won't be at an ICU building either. I'll be at a client's place but I've still got to believe that I'm ICU, that I'm one of these 85,000 that are gonna 'deliver high performance'. I'm a bit cynical about that but it's got something to it - it kind of puts you out there straight away.' (Adam - trainee)

This notion of 'being' the company, at least in the eyes of the client, touches on the second key feature of the consulting labour process: the need to be seen to be 'adding value', not only for the client, but also to generate new business for ICU whilst completing a contracted project.

\section{'You've got to be able to kill what you eat'}

As there is no dedicated sales function at ICU it becomes, at least partly, the project teams' responsibility to generate additional business. As with many professional service organizations, as consultants progress through the seniority ranks the need to network and generate additional business becomes more and more central, colonising their social and personal lives (Grey, 1994). As ICU operated a system of internal promotion, this ability to generate new business was a crucial factor in determining promotion, a point that trainers were at pains to point out. In the first two presentations the trainers headlined the imperative to sell:

'ICU has 90,000 people to pay, if we stop selling how long do you think we have before we all go bankrupt?' - 'ICU Overview' presentation

'What you sell, you deliver - you've got to be able to kill what you eat - if you can't kill then you've got a problem and if you can't eat that's another problem' - 'Leadership and Core Values' presenter

The first day also included a presentation on ICU's branding strategy, at which several of the joiners expressed surprised, not considering it relevant to their role as analysts. When probed as to why they thought this material was delivered to them on their first day, the recruits interpreted 
it as further stressing the need to sell or as additional encouragement to suffuse themselves into the ICU culture. In either case the emphasis was on ensuring that the recruits understood the need to perform according to the script laid out by the ICU values, for an audience that combined both internal assessors and the client. Indeed one slide, entitled 'Your role in building ICU', instructed joiners that they must ask themselves: 'How can I be perceived by clients as delivering high performance?'

This notion of 'performance' was central to the training as clients' perceptions of ICU, and therefore future sales and revenues, depend entirely upon the analysts' performance at the client site. In this sense, whilst many of the presentations exhorted the new starters to accept ICU's values and conform to its culture, this wasn't treated as an end in itself or an a priori 'good'. The key issue in the training was the new starters' ability to conform their behaviour to those patterns expected from an ICU analyst. Whilst behavioural compliance (Ogbonna and Harris, 1998) was the goal of the training, the most effective means of ensuring this compliance was through encouraging the recruits to internalise key values and to work directly through the recruits' subjectivity. This ambivalence is captured by a quote from Katie, one of the facilitators, who described the orientation training's overarching goal as being 'about teaching and showing them the culture - the way ICU wants them to behave'.

\section{Learning to perform: the act of consulting}

The theme of behaviour and performance was brought to the fore in the afternoon programme. Joiners participated in a session conducted by a freelance drama group, SDL, in which three trainers acted out a range of scenarios that the graduates might face in their work. In each of these scenarios joiners were asked to advise the trainer, in-character as a new hire, how to adapt his or her behaviour in order to come across in a more 'appropriate way', thereby avoiding embarrassment, damage to the company's image, or tensions with colleagues. The scenarios were delivered in a humorous and entertaining way and covered a number of possible uncomfortable situations, such as a competitor overhearing a consultant discussing details of a confidential project bid whilst on a train, or a new joiner being cordoned at the coffee machine by a client wanting information on a project she had yet to be briefed on. 
Despite the evident humour it was clear that these dramatic performances were intended as rehearsals for the recruits' actual performance in the field, where the audience would include current and future clients as well as supervisors and peers. For this reason the changes that the SDL actors underwent on the advice of the trainees had to be made believable. To achieve this the SDL actors had to remain 'in-character' throughout. As one of the ICU trainers put it:

\footnotetext{
'We try to keep the characters still in-character even though they're having the [advice] so they don't suddenly become the perfect ICU graduate from starting off being really terrible: they're still the same person. That's more getting the audience to think about how you can manage yourself - still being yourself but managing yourself' (Diane - trainer)
}

In treating the behaviours expected of the new recruits as performances the clear goal was behavioural compliance, but the way that this was achieved was through the use of a dramaturgically realised technique of self-management. In developing the behaviours necessary for the effective performance of the consulting labour-process, the recruits were subjectively reconfigured as 'professionals', acting out the correct forms of behaviour without regard to their own emotional or usual social responses. This 'professional' identity demanded a degree of selfcontrol that would ensure appropriate conduct and performance regardless of immediate subjective response. In developing this 'professionalism' the consultants were similar to the emotional labourer's studied by Höpfl (2002) who developed the 'dual consciousness' of an actor or a prostitute who achieves 'autonomy and self-possession' by detachment and alienation: 'a willingness to submit to the performance; in effect it means the actor can say 'I can play this role because I am detached from it' (Höpfl, 2002: 260). Whilst prostitutes, actors and emotional labourers must be self-controlled in order to deliver synthetic, but apparently authentic, emotional performances, the professionalism of the consultants was closer to a suppression of emotion. This performance of professional self-control was an integral part of the repertoire the new consultants were being encouraged to develop.

\section{A 'professional ethic of behaviour'}

In adopting this professional demeanour the recruits were actively working upon their 
subjectivity, not necessarily to internalise all of the espoused values of ICU and identify completely with the company's culture, but rather to inculcate a professional subjectivity of disciplined self-control which would enable them to perform in accordance with ICU's espoused values regardless of their personal values, opinions or emotions. This professionalism was itself the core value that recruits were expected to internalise and which was attended to and judged by trainers during the programme. As one of the trainers rather candidly put it, the drama training was directed at 'managing behaviour' in accordance with ICU's values of 'discretion, professionalism, tact, [and] confidentiality', with a 'professional ethic of behaviour' (John trainer). This 'professional ethic of behaviour' placed tightly prescribed limits upon what was, and was not, acceptable behaviour, limits that extended beyond a narrow conception of the workplace to circumscribe elements more conventionally considered to be part of an employee's social life.

In the second of the role-play scenarios an analyst was depicted on a Friday evening after work when a director of the client company approaches her in a local bar and starts discussing the project. The role-play culminates with the intoxicated analyst revealing delicate information about her team's forthcoming recommendations for redundancies at the client firm, thereby offending the director. At the close, the in-role trainer turned to ask her joiner audience 'Is it ok for me to be tipsy?' which was greeted with a chorus of replies to the effect of 'Not in the presence of a client'. Even without contesting the undesirability of the analyst's behaviour in this scenario, this example highlights the extent to which joiners apparently accepted the organization's right to proscribe their actions outside working hours. Behavioural compliance seemed to be demanded, and supplied, within extremely wide bounds, bounds laid down by an ethos of professionalism rooted in the analyst's identity as a professional above all else.

One facilitator confirmed the breadth of ICU's expectations regarding behaviour 'outside of work' adding that, in introducing the joiners to each other, ICU was 'giving them a social group they can mix with... which sort of allows them a chance of having a social life' in spite of the long hours they are expected to work. ICU's management of its employees' conduct and social lives was designed to ensure that their performance both on and away from the client site was carefully controlled in line with the company's 'professional ethic of behaviour'. It also provided 
a ready made peer-group whose interactions would facilitate the reinforcement and policing of this ethic. In conjunction with the company's long-hours culture, the new recruits were swiftly denuded of external points of reference from which to challenge either the value system implicit in ICU's 'professional ethic of behaviour', or the extension of its influence into every aspect of their lives.

\section{Cynicism, Performance and Role Distance: Compliance or Control?}

In interviews, several of the new analysts expressed cynicism about certain parts of the training, and the extent to which ICU really had a distinctive culture. Mark (recruit) thought listening to be 'a challenge at times' and considered the presentation of its culture to be 'quite cheesy'. Similarly, Matthew (recruit) was disparaging about the relevance of the 'Leadership and Core Values' presentation:

'I don't know how much people want to listen to the whole leadership/values talks - we've experienced them in our University lives, other jobs - you pretty much know that sort of stuff...core values and leadership exist in any of these big companies - they all preach the same thing'

Despite this, the recruits were conscious of having to make a performance of listening and of having this performance observed both by the trainers and the other recruits. Adam (recruit) spoke of there being 'a huge pressure in the room...you do feel that everyone's watching'. He continued:

'I've never been in such an attentive group and the speakers weren't interesting! And they weren't saying anything that anyone didn't know already - just people, you know, trying to look engaged'

Or as Harriet, another recruit, put it:

'Sometimes I feel that there's maybe someone important watching to see if I'm paying attention...earlier I was surprised [be]cause I was doodling away and [the presenter] said 'oh yeah there's a [higher ranking analyst] about to give a presentation', she was sitting right behind me....You feel all the time... that people may be on the lookout to see who's paying attention' 
This surveillance was not paranoia on the part of the recruits, but a clear recognition of the omnipresent gaze of assessment. As one of the trainers (Andrew) explained in interview:

'...you need to keep a little bit of health attention. So they need to be aware that they will be asked to contribute, that will at times require a certain amount of intellectual input and energy...at times they will be very visible to the rest of the class... you need that tension there'

Whilst a full analysis of the use of surveillance, and the significance of peer-surveillance in particular, is beyond the scope of the current paper, these observations are crucial as they demonstrate that despite a certain cynicism in the recruits' responses to the content of the presentations, the situation was such that they actively performed the role of engaged, attentive listener despite their personal disengagement. This alienated performance was entirely in line with the kind of professionalism expected from the recruits and encouraged through the promulgation of ICU's 'professional ethic of behaviour' in the training.

These comments suggest that the recruits were adopting the strategy of 'working at a cynical distance' (Fleming and Spicer, 2003) and maintaining a clear separation between their real selves and their performances. Given the intense pressure to perform and the cut-throat up-or-out career system, these 'survival strategies' (Noon and Blyton, 2002) of defensive distancing are entirely understandable. In such a situation an overidentification with corporate values is risky as it puts one's sense of self on the line along with one's income and career. But overidentification can also be dysfunctional for the organization. As Peter Fleming has noted, overidentification can be a 'seditious practice' and an extremely effective form of resistance: a kind of cultural equivalent of the work-to-rule (Fleming, 2005: 54; Fleming and Sewell, 2002; Spicer, 2001). In an economic and business context characterised by flexibility and change, such strong identification can be doubly problematic for organizations that may need to 'realign their core values' at a 
moments notice, according to the whims of management fashion. In the ICU case, these twin dangers of strong identification - the psychic danger for the analysts and the danger of inflexibility for the company - were resolved by keeping the content of the corporate values at a safe distance. Objectified onto powerpoint slides and slogans, the values could easily be learned and performances could readily be aligned with them. This distance was developed through two techniques: the recruits own cynical distancing, articulated in the interviews, and ICU's use of dramaturgical role distancing in the form of the training session.

Nevertheless, at a deeper level, the underlying ICU value of a 'professional ethic of behaviour' was simultaneously presented as the over-arching value system which recruits were expected to identify with. This 'ethic' complemented the recruits' cynical distancing, and the dramaturgical distancing developed in the training session, by combining them in a 'professional' distance which could be maintained independently of the recruits' own subjective sensibilities, such as a squeamishness about 'cheesy' values or becoming a 'Stepford Wife', and would penetrate to the core of the recruits' subjectivities. In combination with a strong programme of peer-socialisation, long hours, on-going performance appraisal and intense career competition, this 'professional ethic' could be sustained as both a survival strategy and as an effective means of organizational control. In this it seems that ICU have learned the lesson from critical studies of organization that cynical distancing and 'compliance without conformity' can offer a more effective form of control than overidentification (Fleming and Sewell, 2001:864; Kunda, 1992).

\section{Discussion and Implications}

Peter Fleming (2005) has recently questioned whether 'distancing' is really an appropriate 
metaphor for cynicism as it implies the preservation and protection of a core self, separate from and preceding that from which it is 'distanced'. According to Fleming this is to fundamentally misunderstand the essentially open-ended and constructed processes of subjectivization where cynicism is "the production or constitution of selfhood rather than merely its defence or distancing" (2005: 54). In this we absolutely agree with him. Through both cynical and dramaturgical 'distancing', the recruits were engaged in the process of production of a selfalienated subjectivity. Through these processes both the 'core' and the alienated, 'professional' self were produced. We are, however, much less optimistic than Fleming about the results of this process of subjectivisation. For Fleming, cynicism is a moment of resistance as it 'crafts empancipatory space within relations of domination' (2005: 55) through the active constitution of a self that is separate from the normative control of the corporate value system. As this case study suggests, however, in at least some cases this very process of splitting and the production of 'distance' becomes reappropriated through discourses of 'professionalism' and 'performance' to serve the interests of the organization.

If our analysis is correct, it has implications for the project of critique within management and organization studies more generally. The recruits in the case study were well versed in the discourses of critical management studies (CMS) and cited both Foucault and Orwell without any prompting when discussing surveillance and assessment on the training. Whilst the precise processes require further research, from the case discussed here it would appear that a familiarity with the discourses and theories of CMS gave the recruits little with which to resist the processes of subjectivization deployed in the training. On the contrary, these discourses appear to have actively contributed to these processes of subjectivization precisely by complementing the 
'distancing' at their core. Instead of creating an enlightened distance and space for 'emancipation', these processes of intellectual and cynical distancing appear to have complemented the forms of professional and performative distancing developed in the training session.

But perhaps this should not surprise us. In other areas, the limits of cynicism have been well documented. In his wide ranging study of modern European culture, Peter Sloterdijk traces the development of cynicism as a form of 'enlightened false consciousness': that “modernized, unhappy consciousness, on which enlightenment has labored both successfully and in vain", which "has learning its lessons in enlightenment, but... has not, and probably will not be able to, put them into practice" (1987: 5). In the same way, the recruits, at least in interview, were able to articulate a critique of the power relations playing upon them, but precisely by intellectualising them and labelling them, were able to align these insights with the more general process of 'professional' distancing being developed through the training. After all, the main focus of this training was to enable a professional performance, regardless of the consultant's subjective state. That this alienated distance is itself part of the form (through dramaturgy) and content (through the discourse of professionalism) of subjectivization is precisely what appears to distinguish this form of control from more conventional models of cultural/normative control.

\section{Conclusions}

We started this paper with the argument that understanding control in contemporary workplaces requires an appreciation of the ways in which subjectivization takes place at a number of sites separate from the point of production. In particular we argued for the significance of training as a central moment of workers 'preparing to work' (Dyer-Witheford, 1999). In the preparation of 
new graduate-recruits for the consulting labour process, training is predominantly focussed on aligning the behaviours of recruits with the organization's professional ethic of behaviour. Whilst this 'ethic' allows for a degree of autonomy and cynicism concerning specific corporate values, such distancing must be managed by the maintenance of a professional demeanour. As this professionalism is expected to extend beyond the workplace and into aspects of the new recruits' social lives, the expectations placed on this 'ethic' exceed a token behavioural compliance. Specific values may be questioned and merely complied with, but the organizing ethic of professionalism should constitute a cornerstone of the new recruits' subjectivity.

This subjectivity is itself maintained and reinforced by a long-hours culture where socialising is predominantly within a peer-group of fellow employees, thereby cutting the recruits off from external social networks that might otherwise provide a point for critical reflection upon specific corporate values and the organizing value of ICU's professional 'ethic'. Nevertheless, from our analysis it appears unlikely that such a 'critical distance' would have much of an effect upon this process of subjectivization, precisely because this process proceeds by means of the production of a subjective 'distance' from the espoused corporate values. As the articulation of cynical and critical perspectives on the process in the interviews suggests, such a 'distance' has little effect on the performative compliance willingly given by the recruits, nor upon the deeper processes of socialization into a 'professional ethic of behaviour'.

Of course, further research is required to determine how far this 'preparation' translates into effective control over the labour process at the point of production, but this is not to diminish training as a mere 'preparation' for the real work which will come later. In a very real sense these training events are a point of production: the production of labour power (Harvie, 2006). As we have argued throughout this paper, the consultants' on-site performance is the product being consumed by the client. Whilst the (re)production of this form of professional labourpower is clearly on-going, induction training of the sort discussed in this paper is a crucial first moment in this process and fundamental to new recruits' understandings of what kinds of performance are acceptable for, and demanded of, an ICU-branded consultant, for rehearsing such performances, and for developing a 'professional ethic of behaviour' that will enable such performances to be sustained in a variety of situations where the work/non-work boundaries are 
porous. When studying knowledge-intensive labour processes like consulting the point of production must be extended to incorporate all moments of the production of such subjectivities. Indeed, we might even go so far as to suggest that in such situations the reproduction of the social-subjectivities that characterise these forms of labour-power are the primary labour processes of the industry. After all, this is where the performances that will be consumed later, in the formal labour-process of consulting, are actually produced. 


\section{References}

Ackroyd, S. and Crowdy, P.A. (1990). 'Can culture be managed?' Personnel Review, 19 (5):313.

Ackroyd, S. and Thompson, P. (1999) Organizational Misbehaviour. London: Sage.

Alvesson, M. (2004) Knowledge Work and Knowledge Intensive Firms. Oxford: Oxford University Press.

Barker, J. (1999) The Discipline of Teamwork: Participation and Concertive Control. London: Sage.

Barker, J. (1993) 'Tightening the Iron Cage: concertive control in self-managing teams' Administrative Science Quarterly, No.38: 408-437

Böhm, S. (2003) 'The Consulting Arcade: A walk through fetish-land', Tamara: Journal of Critical Post-modern Organization Science, 2(2): 20-35.

Boltanski, L. and Chiapello, E. (2005) The New Spirit of Capitalism. London: Verso.

Braverman, H. (1974) Labour and Monopoly Capital: The Degradation of Work in the Twentieth Century. Now York: Monthly Review Press.

Burawoy, M. (1982) Manufacturing Consent: Changes in the Labor Process Under Monopoly Capitalism. Chicago: University of Chicago Press.

Callaghan, G. and Thompson, P. (2002) 'We recruit attitude: The selection and shaping of routine call centre labour', Journal of Management Studies, 39(2): 233-254.

Casey, C. (1995) Work, Self and Society, London \& New York, Routledge

Cohen, S. and Taylor, L. (1992) Escape Attempts: The Theory and Practice of Everyday Life, $2^{\text {nd }}$ edition. London: Routledge.

Collinson, D. (2003) 'Identities and insecurities: Selves at work', Organization, 10(3): 527-547.

Collinson, D. (1992) Managing the Shopfloor: Subjectivity, Masculinity and Workplace Culture. Berlin: Walter de Gruyter.

Dyer-Witherford, N. (1999) Cyber-Marx: Cycles and Circuits of Struggle in High-Technology Capitalism, Urbana, IL: University of Illinois Press.

Fleming, P. (2006) “'Just be yourself’ (or else!): Identity management, resistance and the new spirit of capitalism in contemporary organizations', paper presented to the Essex Management Centre, University of Essex, 29th November, 2006. 
Fleming, P. (2005) 'Metaphors of resistance', Management Communication Quarterly, 19(1): $45-66$

Fleming, P. \& Sewell, G. (2002) 'Looking for the Good Soldier Sveijk: Alternative Modalities of Resistance in the Contemporary Workplace, Sociology, Vol.36 No.4: 857-873

Fleming, P. and Spicer, A. (2003) 'Working at a Cynical Distance: Implications for Power, Subjectivity and Resistance' Organization, Vol.10 No.1: 157-179

Frenkel, S, May, T., Korzynski, M. and Shire, K. (1998) 'Beyond bureaucracy? Work organization in call centres', International Journal of Human Resource Management, 9(6): 957-979.

Gabriel, Y. (1999) 'Beyond Happy Families: A Critical Revelation of the Control-ResistanceIdentity Triangle', Human Relations, Vol.52 No.2: 179-203

Garson, B. (1988) The Electronic Sweatshop. New York: Simon and Schuster.

Glucksmann, M. (2000) Cottons and Casuals: The Gendered Organization of Labour in Time and Space. Durham: Sociology Press.

Grey, C. (1994) 'Career as a project of the self and labour process discipline', Sociology, 28(2): 479-97.

Hancock, P. and Tyler, M. (2001) Work, Postmodernism and Organization: A Critical Introduction. London: Sage.

Hardt, M. and Negri, A. (2000) Empire, Cambridge MA: Harvard University Press.

Harney, S. (2007) 'Socialization and the Business School', Management Learning, 38(2): 1-14.

Harvie, D. (2006) 'Value-production and struggle in the classroom', Capital and Class, 88 (Spring): 1-32.

Höpfl, H. (2002) 'Playing the part: Reflections on aspects of mere performance in the customerclient relationship', Journal of Management Studies, 39(2): 255-267.

Jaros, S. and Sells, L. (2004) 'Jacques's (2000) call for a knowledge theory of value: Implications for labour process theory', Electronic Journal of Radical Organization Theory, 8(1). Online at: http://www.mngt.waikato.ac.nz/ejrot/Vol8_1new/Jaros.pdf

Jermier, J. (1998) 'Introduction: Critical perspectives on organizational control', Administrative Science Quarterly, 43(2): 235-256.

Knights, D. \& McCabe, D. (2000) “Ain’t Misbehavin'? Opportunities for Resistance under New Form of 'Quality' Management' Sociology, 34(3): 421-436 
Kunda, G. (1992) Engineering Culture, Philadelphia, Temple University Press.

Lave, J. and Wenger, E. (1991) Situated Learning: Legitimate Peripheral Participation. Cambridge: Cambridge University Press.

Leidner, R. (1999) 'Emotional labour in service work', Annals of the American Academy of Political and Social Sciences, 561: 81-95.

Marx, K (1979) Capital: Volume 1, trans. B. Fowkes. London: Penguin.

McCabe, D. (2000) 'The team dream: The meaning and experience of teamworking for employees in an automobile manufacturing company', in S. Procter and F. Mueller (eds.) Teamworking. Basingstoke: Macmillan Business.

Metcalfe, A. (1992) 'The curriculum vitae: Confessions of a wage-labourer', Work, Employment and Society, 6(4): 619-641.

Noon, M. and Blyton, P. (2002) The Realities of Work, Second Edition. Basingstoke: Palgrave.

Ogbonna, E. and Harris, L. (1998) 'Managing Organizational Culture: Compliance or Genuine Change?', British Journal of Management, 9(4): 273-288.

Ray, C.A. (1986) 'Corporate Culture: The Last Frontier of Control?', Journal of Management Studies, Vol.23 No.3:287-297

Robertson, M. \& Swan, J. (2003) “Control - what control?’ Culture and ambiguity within a knowledge intensive firm', Journal of Management Studies,40(4): 831-858.

Ross, A. (2003) No-Collar: The Humane Workplace and its Hidden Costs. Philadelphia: Temple University Press.

Sewell G. (1998) 'The discipline of teams: The control of team-based industrial work through electronic and peer surveillance', Administrative Science Quarterly, 43(2): 397-428.

Sewell, G. and Wilkinson, B. (1992) ' Someone to watch over me': Surveillance, discipline and the just-in-time labour process', Sociology, 26(2): 271-289.

Sloterdijk, P. (1987) Critique of Cynical Reason, trans. M. Eldred. Minneapolis: University of Minnesota Press.

Spicer, A. (2001) 'Out of the cynical bind? A reflection on resistance in Fight Club', ephemera, 1(1): 92-102.

Taylor, P. and Bain, P. (1999) “An assembly line in the head': work and employee relations in the call centre', Industrial Relations Journal, 30(2): 101-117.

Thompson, P., Warhurst, C. and Callaghan, G. (2001) 'Ignorant theory and knowledgeable workers: Interrogating the connections between knowledge, skills and services', Journal of 
Management Studies, 38(7): 923-942.

Watson, T.J. (1994) In Search of Management: Culture, Chaos \& Control in Managerial Work. London: International Thompson Business Press.

Willis, P. (1978) Learning to Labour, London: Ashgate.

Willmott, H. (1993) “"Strength is ignorance; slavery is freedom”: Managing culture in modern organizations', Journal of Management Studies, Vol. 30 No.4: 515-552 